Institute of $\mathbf{F}_{\text {ood and }} \mathbf{A}_{\text {gricultural }} \mathbf{S}_{\text {ciences }}$

\title{
Impact of the Bioterrorism Threat on the Food Industries ${ }^{1}$
}

Douglas L. Archer and Fred H. Degnan²

The events of September 11, 2001 and the aftermath anthrax incidents have refocused the food safety concerns and priorities of regulatory agencies. The threat of terrorism aimed at the food supply and assuring biosecurity have become nightly news stories. Can biosecurity be supplied by the regulatory agencies, or will responsibility largely fall on the growers, packers, shippers, and processors of our food? The question almost answers itself: the burden falls on the regulated industry to assure the safety of its products.

What would such an attack on the food supply accomplish? It is difficult to envision that widespread serious harm and death would result, at least no more so than we experience in large outbreaks of food-borne disease. Nevertheless, even if relatively little harm to human health resulted-economic consequences could be great, and consumer confidence in the food supply and the regulatory agencies, shaken.

The Tylenol ${ }^{\circledR}$ tampering episodes of the early 1980s provide a good model of the types of considerations and prophylactic steps the industry should be considering. The episodes energized
FDA-regulated industries to implement meaningful anti-tampering plans, including new or modified drug forms, and tamper-resistant packaging. FDA and the regulated industry developed a cooperative relationship as never before--and industry did the creative problem solving. In the current situation, FDA likely has its hands full in generally improving its state of preparedness and ability to respond to a bioterrorism emergency. Increased inspection of imported foods alone will stress FDA's existing work force, and its program priorities will shift dramatically.

Recognizing that the level of sophistication in the response to potential bioterrorism will vary with the size of a given company, among other factors, there seem to be some common points for food growers, packers, shippers, and processors to consider in light of the current circumstances.

- In the absence of better knowledge about the nature and seriousness of a threat, the distinction between under-reaction and over-reaction is blurred.

- A strong focus on facility and personnel security is a must. Where possible, background checks for ALL personnel should be required. NO

1. This document is FSHN02-8, one of a series of the Food Science and Human Nutrition Department, Florida Cooperative Extension Service, Institute of Food and Agricultural Sciences, University of Florida. Publication: September 2002. Reviewed by C.A. Sims, Ph.D., professor; and S.S. Percival, Ph.D., professor, both of the Food Science and Human Nutrition Department, Cooperative Extension Service, Institute of Food and Agricultural Sciences, University of Florida, Gainesville, FL 32611-0370. Please visit the EDIS Web Site at http://edis.ifas.ufl.edu. This document is being reprinted by permission of the Institute of Food Technologists and author Degnan.

2. D.L. Archer, Ph.D., professor, Food Science and Human Nutrition Department, Cooperative Extension Service, Institute of Food and Agricultural Sciences, University of Florida, Gainesville, FL 32611-0370 and F.H. Degnan, Partner, King \& Spalding, Distinguished Lecturer, Catholic University School of Law.

The Institute of Food and Agricultural Sciences is an equal opportunity/affirmative action employer authorized to provide research, educational information and other services only to individuals and institutions that function without regard to race, color, sex, age, handicap, or national origin. For information on obtaining other extension publications, contact your county Cooperative Extension Service office. Florida Cooperative Extension Service/Institute of Food and Agricultural Sciences/University of Florida/Christine Taylor Waddill, Dean. 
ONE who is not so authorized should have access to the finished food product

- Do you know who is delivering raw material to your facility, and who is transporting finished product out? What security precautions are those entities taking?

- Anti-tampering plans, if they exist, should be re-evaluated. If they don't exist, they should be developed, adopted, and implemented.

- GAPs, GMPs, and HACCP plans should be re-evaluated. Are they sufficient to protect from purposeful acts of food contamination? Do they cover the following points?

1. raw material integrity

2. packaging integrity

3. air flow systems

4. end-line activities

5. storage and transportation

- Consumer complaint handling practices should be checked and fine tuned.

- Recall procedures should be checked and fine tuned. Know who you would contact at your local FDA office and how to reach them.

- Know who could provide quick access to analytical methods or microbiological or chemical analyses of your products on an emergency basis. Have those contact numbers readily available.

- Improve preparedness among all employees through regular training or drills. Develop a heightened understanding of the problem, its consequences, and that increased awareness on the part of all is an important component of prevention.

- Know that procedural changes in handling a "possible problem" are called for in the face of a possible bioterrorism event. The balance of internal (company) investigation and FDA notification favors early agency notification. False alarms will be one price of vigilance.
- Be aware that FDA, CDC, and state agriculture and health agencies will likely be in a "help mode" as previously seen in product tampering incidents. Everyone recognizes that terrorism is the fault of the terrorists, not of a farm or a food company.

The above list is certainly not intended to be all-inclusive of possible preventive steps. Large companies will likely have the resources to take a risk-analysis approach to their operation, and use a team of experts to devise prevention strategies, intervention strategies, containment strategies, and educational strategies--all aimed at dealing with possible bioterrorism. The sharing of strategies and experience among companies with similar attributes, or sharing facilitated by trade organizations, will strengthen the whole of the effort, and should be encouraged by government. At all costs, complacency needs to be avoided for, as time passes, the specter of possibly more and more sophisticated terrorist acts looms. 